- Additional material is published online only. To view please visit the journal online (http://dx.doi.org/10.1136/ medethics-2014-102596).

${ }^{1}$ University of California, San Diego, California, USA

${ }^{2}$ Department of Pharmacology and Physiology, Georgetown University Medical Center, Washington DC, USA

Correspondence to Dr Adriane Fugh-Berman, Department of Pharmacology and Physiology, Georgetown University Medical Center, 3900 Reservoir Rd. N.W., Med-Dent SE 402, Washington DC 20007, USA; ajf29@georgetown.edu

Received 24 November 2014 Revised 22 May 2015 Accepted 2 June 2015 Published Online First 29 June 2015
CrossMark

\author{
To cite: Meixel $A$, \\ Yanchar E, Fugh-Berman A \\ $J$ Med Ethics 2015;41:
}

859-862.

\title{
Hypoactive sexual desire disorder: inventing a disease to sell low libido
}

\author{
Antonie Meixel, ${ }^{1}$ Elena Yanchar, ${ }^{1}$ Adriane Fugh-Berman ${ }^{2}$
}

\section{ABSTRACT}

Condition branding is a marketing technique in which companies develop conditions concurrently with developing drugs; examples include gastro-oesophageal reflux disease, premenstrual dysphoric disorder, social anxiety disorder, erectile dysfunction and hypoactive sexual desire disorder. Although it is illegal for pharmaceutical companies to market drugs prior to regulatory approval, there are no restrictions on marketing diseases, and industry seeks to establish a disease state in the minds of clinicians years before an expected drug launch. Continuing medical education (CME) courses are an important part of promotion prior to drug approval and have become a key marketing tool for increasing clinician receptivity to new products. We systematically identified 14 free, internet-based, industryfunded, accredited CME modules on hypoactive sexual desire disorder in women which came out before a new drug, flibanserin, was being considered for regulatory approval in the USA. Common themes in these modules included the following: (1) Hypoactive sexual desire disorder is common, underdiagnosed and can have a profound effect on quality of life. (2) Women may not be aware that they are sick or distressed. (3) Simple questionnaires can assist clinicians in diagnosing the disorder. (4) It is problematic that there are medicines available to treat sexual problems for men but not women. In fact, there is no scientifically established norm for sexual activity, feelings or desire, and there is no evidence that hypoactive sexual desire disorder is a medical condition. Hypoactive sexual desire disorder is a typical example of a condition that was sponsored by industry to prepare the market for a specific treatment.

Disease branding or condition branding is a marketing technique in which a company adopts-or invents-a condition and then develops the so-called disease state prior to or concurrently with marketing therapies for that condition. According to industry articles, while product branding promotes a specific solution, condition branding 'educates consumers, physicians and other stakeholders about the problem'. ${ }^{1}$ For example, when the blockbuster drug Prozac (fluoxetine) was nearing the end of its patent life, the company sponsored the creation of the condition premenstrual dysphoric disorder, depicted as a more serious form of premenstrual syndrome, before marketing Sarafem (fluoxetine), which was simply repackaged Prozac. ${ }^{2}$ The condition previously known as shyness was condition-branded as social anxiety disorder, designed to provide a marketing edge for Paxil (paroxetine), a serotonin reuptake inhibitor that otherwise risked being sidelined as just another 'me-too' antidepressant. ${ }^{1}$
The three strategies for 'fostering the creation of a condition and aligning it with a product' are:

- elevating the importance of an existing condition;

- redefining an existing condition to reduce a stigma;

- developing a new condition to build recognition for an unmet market need. ${ }^{2}$

Examples follow:

Elevating the importance of an existing condition: from heartburn to gastro-oesophageal reflux disease

The metamorphosis of heartburn to gastrooesophageal reflux disease (GERD) is a recent example of 'elevating the importance of an existing condition'. Heartburn, a benign condition most commonly caused by eating too much or drinking too much alcohol, was renamed and conditionbranded as GERD by the manufacturers of Zantac (ranitidine). To 'raise the bar of seriousness' of GERD, Glaxo created the Glaxo Institute for Digestive Health, which conferred research awards in gastrointestinal health; involved the American College of Gastroenterology; and launched a public relations effort called 'Heartburn across America'. ${ }^{2}$

Redefining an existing condition to reduce a stigma: Viagra

To sell Viagra (sildenafil), the condition previously known as impotence was rebranded as erectile dysfunction (ED). ${ }^{2}$ The condition branding of Viagra involved renaming the condition in a way that reduced social stigma and casting it as a highly prevalent, chronic condition that had a serious impact on quality of life. It was important to cast ED as a medical condition, rather than a psychological condition, or a normal effect of ageing. To help medicalise the condition, a questionnaire tool was created that subdivided the condition into mild, moderate and severe versions. ${ }^{1}$ Researchers paid by Pfizer published studies about the high prevalence of ED, the importance of treating it and the availability of questionnaire tools. ${ }^{3}$ Physicians paid by Pfizer were used to promote both the drug and the disease; ${ }^{3}$ efforts were made to expand the market to include even men with rare or transient episodes of failing to achieve or maintain an erection. ${ }^{4}$ One Pfizer-paid physician even suggested that Viagra should be taken on a regular basis to prevent ED. ${ }^{3}$

The runaway success of Viagra, an effective treatment, launched a race to create a drug for women. Although there is no female equivalent to $\mathrm{ED}$, a coalition of pharmaceutical companies, with the help of paid key opinion leaders, funded programmes to increase awareness of 'female sexual dysfunction' among both physicians and consumers in the late $1990 \mathrm{s.}^{5}$ 
Developing a new condition to build recognition for an unmet market need: hypoactive sexual desire disorder

Hypoactive sexual desire disorder was established by industry in 2004 to prepare the market for a testosterone patch for women. ${ }^{67}$ According to the Diagnostic and Statistical Manual of Mental Disorders (DSM), hypoactive sexual desire disorder is characterised by 'persistently or recurrently deficient (or absent) sexual fantasies and desire for sexual activity' that causes 'marked distress or interpersonal difficulty'. ${ }^{8}$ Hypoactive sexual desire disorder was recently dropped from the latest edition of the DSM-5; disorders of desire and arousal have now been combined in the term 'female sexual interest/arousal disorder' (FSI/AD). ${ }^{9}$

Treatments developed to enhance female libido, including the testosterone patch, Viagra (sildenafil), Libigel (a testosterone gel) and flibanserin, have all failed to obtain Food and Drug Administration (FDA) approval. ${ }^{10}$

Of these three, only flibanserin is still in the running. Flibanserin has been rejected twice. A failed antidepressant developed by Boehringer Ingelheim, flibanserin was recast as a treatment for hypoactive sexual desire disorder. ${ }^{6}$ In October 2010, after an FDA advisory committee concluded that there was little evidence that flibanserin increased libido and that the drug caused an unacceptable level of adverse effects, Boehringer Ingelheim abandoned developing the drug and sold it to Sprout Pharmaceuticals in 2011. In October 2013, the FDA denied Sprout Pharmaceuticals permission to market flibanserin. ${ }^{10}$ The company has resubmitted its application and the drug will be reconsidered by the FDA in 2015 .

After the FDA's second rejection of flibanserin in 2013, Sprout launched a public relations campaign, persuading several women's groups, female Congressional representatives and a group of clinicians to complain to the FDA that the agency is 'sexist' for having approved drugs only for male, but not female, sexual dysfunction. A coalition of non-industry-funded advocacy groups supported the FDA's decision. ${ }^{11}$

Marketing a drug begins many years before a drug is expected to be approved. Although it is illegal for pharmaceutical companies to market drugs prior to regulatory approval, there are no restrictions on marketing diseases. It is important that what industry terms a disease state is established in the minds of clinicians in the 'pre-launch' stage of drug development, prior to the availability of a drug. ${ }^{12}$

Key opinion leaders, also called KOLs, are influential physicians or researchers who may be paid by industry to provide promotional talks or continuing medical education (CME) courses. CME events are an especially important part of pre-launch disease state promotion. CME is not regulated as promotion and has become a key marketing tool for increasing clinician receptivity to new products, expanding existing markets, positioning products against competitors, mitigating concerns about adverse effects and promoting unproven off-label uses of marketed drugs. ${ }^{12}$

We decided to examine CME materials on hypoactive sexual desire disorder near the time that flibanserin was first being considered by the FDA to see whether there were any common themes in these modules that could support marketing purposes. Although the invention of female sexual dysfunction and hypoactive sexual desire disorder has been well-documented in medical journal articles ${ }^{5-7} 13$ and Sex, Lies, and Pharmaceuticals, a book by Australian journalist Ray Moynihan and Canadian researcher Barbara Mintzes, ${ }^{14}$ no previous publication to our knowledge has examined themes in CME materials prior to regulatory consideration of a drug.

In 2010, the year flibanserin first came before the FDA, we identified free, internet-based CME modules that focused on hypoactive sexual desire disorder in women by searching Google for 'Hypoactive Sexual Desire Disorder' or 'HSDD' combined with
'CME' or 'Continuing Medical Education'. We examined the first 100 hits (10 Google pages) for each search and then excluded duplicate modules, modules pertaining to hypoactive sexual desire disorder in men and modules that were webcast-only with no text component. No other exclusion criteria were applied.

Fourteen CME modules on hypoactive sexual desire disorder in women were identified. ${ }^{15-28}$ All were fully accredited CME modules, approved by a provider accredited by the Accreditation Council of CME. All 14 CME modules disclosed funding through educational grants by Boehringer Ingelheim. Additionally, 12 of 14 modules had at least one author with financial ties to Boehringer Ingelheim which was revealed under faculty disclosures (see online supplementary appendix for the list of CME courses assessed and financial ties of authors).

All authors reviewed all modules and identified themes and messages common to the modules by consensus. To our knowledge, this is the first analysis of marketing messages in a subjectspecific set of CME modules.

Marketing messages often focus on how a condition is underdiagnosed, widespread and affects quality of life, and how current treatments are absent, inadequate or problematic. ${ }^{29} \mathrm{CME}$ messaging about hypoactive sexual desire disorder fits this template: hypoactive sexual desire disorder was cast as a common, underdiagnosed problem that has a profound adverse effect on quality of life and the lack of treatments for women's sexual problems was presented as an urgent unmet need. Specific marketing messages that we identified within the CME modules included the following:

1. Hypoactive sexual desire disorder is very common and underdiagnosed.

2. Hypoactive sexual desire disorder can have a profound effect on quality of life.

3. Women may not be aware that they are sick or distressed.

4. Hypoactive sexual desire disorder and distress can have other names.

5. Clinicians should initiate conversation with their patients about their sexual health.

6. Clinicians find it difficult to discuss their patients' sexual concerns and lack training and confidence in the diagnosis of sexual problems.

7. Clinicians need tools and resources to help them diagnose hypoactive sexual desire disorder.

8. Simple tools, including the decreased sexual desire screener (DSDS) and Female Sexual Function Index (FSFI) can assist clinicians in diagnosing hypoactive sexual desire disorder.

9. A major barrier to clinicians talking about hypoactive sexual desire disorder/female sexual dysfunction is the lack of medications.

10. It is problematic that there are medicines available to treat sexual problems for men but not women.

\section{IS HSDD AN EPIDEMIC?}

Hypoactive sexual desire disorder is consistently described as the most common female sexual dysfunction, although no module cited a reference for this specific assertion. A commonly cited industry-funded study published in 1999 reported that $43 \%$ of women have a sexual problem; however, this study never states that hypoactive sexual desire disorder is the most common sexual problem. ${ }^{30}$ Also, the lead author told a BMJ reporter that the study was not intended to represent the number of women with a treatable medical condition. ${ }^{13}$

All modules assessed suggested that hypoactive sexual desire disorder was a significant health problem. For example, one module states that 
Women who have Hypoactive Sexual Desire Disorder will express frustration, anger, diminished self-esteem, a sense of hopelessness, and a sense of decline in their femininity. ${ }^{19}$

Another module invokes an adverse effect on relationships:

Hypoactive Sexual Desire Disorder (HSDD) ... causes considerable distress as well as interpersonal difficulties. ${ }^{23}$

The presence of a problem may be hidden even to the patient.

Women may not always be aware that they have a sexual dysfunction. ${ }^{17}$

Women often present with the complaint of loss of desire without awareness of the complexity of the concept. ${ }^{20}$

A woman who is highly interested in sex, just not with her current partner, can still qualify for a diagnosis of 'situational HSDD', described as

a woman previously had sexual desire for her current partner but now lacks sexual interest in that individual, although she still has desire for sexual stimulation alone or with someone other than her present partner. ${ }^{23}$

Distress is a necessary symptom for the diagnosis of hypoactive sexual desire disorder, but one CME module explains that some patients may

"not identify with the term 'distress," which they interpret "as meaning anxiety, fear, or concealing the problem; they preferred terms such as 'stress-inducing,' 'bothersome,' 'frustrating,' and 'causing concern."”17

Another module cites a study that

... found that neither physicians nor patients were comfortable with the term "Hypoactive Sexual Desire Disorder.[...] Similarly, neither group was particularly comfortable with the term 'distress. ${ }^{16}$

Physicians are urged to bring up the subject, because 'the topic of sexual dysfunction may never come to light if the responsibility for initiating a discussion is left to the patient' ${ }^{19}$

One module notes that '... patients may not know or like specific terms that describe their sexual dysfunction'; ${ }^{20}$ another states that the term hypoactive sexual desire disorder should not be used, instead women should be asked if they experience a 'decrease in sexual desire,' 'low desire' or are 'less interested in sex'. ${ }^{17}$

A woman who is happy with her sex life may still qualify for a diagnosis of hypoactive sexual desire disorder if her partner is dissatisfied, because of 'marked interpersonal difficulties with her husband because of her reduced interest in sex'. ${ }^{18}$

The lack of medications for female sexual dysfunction or hypoactive sexual desire disorder is presented as a problem.

The absence of any FDA-approved pharmacologic treatments for female sexual disorders leaves many healthcare providers worried that if they openly communicate with their female patients about sexual problems, they will have nothing to offer by way of treatment. ${ }^{1}$

Clinicians may also be less likely to raise issues when they feel that they have no effective treatment options to offer a patient. ${ }^{17}$

Another cites a study that states

... providers were frustrated by the lack of easy and uncomplicated treatment options for HSDD. ${ }^{16}$

Some modules address clinicians' lack of confidence in addressing sexual issues. For example, one module states that
One of the most significant practice barriers to physician initiation of sexual health discussions with patients is lack of knowledge/training in sexual medicine. ${ }^{25}$

However, rather than encouraging clinicians to increase their own knowledge of and comfort with sexual issues, these modules reduce sexual counselling to a simple questionnaire that 'takes less than 15 minutes, can be used by healthcare providers who are not experts in sexual disorders to diagnose generalized, acquired HSDD'. ${ }^{17}$

\section{QUESTIONABLE QUESTIONNAIRES}

Most or all diagnostic tools for female sexual dysfunction were developed by manufacturers developing drugs to treat the condition. These include the 19-item FSFI, supported by Bayer and Zonagen; the sexual function questionnaire, funded by Pfizer; the profile of female sexual function, by Proctor and Gamble; and the DSDS by Boehringer Ingelheim. ${ }^{13}$

The DSDS consists of five yes-or-no questions that '... may be filled out by patients in the waiting room'. ${ }^{19}$ A scoring guide is provided. The FSFI contains a long list of questions and a scoring system, but no information on interpreting the scores. ${ }^{31}$ It is apparently up to the clinician to determine who passes or fails. The researcher who published the questionnaire confirmed that there are no cut-off scores (Raymond Rosen, Ph.D., Robert Wood Johnson Medical School, personal communication).

The first question in the FSFI questionnaire asks, 'Over the past 4 weeks, how often did you feel sexual desire or interest?' and the patient is given options that range from 'almost never or never' to 'almost always or always'. ${ }^{31}$ A woman who feels sexual desire for about $50 \%$ of her waking hours scores only 3 out of 5 on the first question. To score a 5, one must feel sexual desire 'always or almost always'.

\section{DISCUSSION}

CME modules on hypoactive sexual desire disorder tell clinicians that they are responsible for bringing up sexuality issues, acknowledge their discomfort and lack of expertise and reassure them that a simple questionnaire will fulfil their clinical obligations.

There is no scientifically established norm for sexual activity, feelings or desire. Decreased interest in sex may be temporary and can be affected by life stresses, relationship problems, illness, medication, fatigue or boredom. Some causes of diminished libido, if problematic, can be addressed by counselling: psychological treatments have been shown to be effective. ${ }^{32}$ Underlying causes-for example, depression—should be treated. Many pharmaceutical drugs, including serotonin reuptake inhibitors and antipsychotics, can lower libido, ${ }^{33}$ in which case adjusting medication regimens may help.

There are certainly women who are troubled by low libido, but there is no reliable scientific evidence that hypoactive sexual desire disorder is a real medical condition. Invented diagnoses may outlive the drugs for which they were invented. Although Boehringer Ingelheim did not create hypoactive sexual desire disorder, the company apparently attempted to brand the condition through CME modules available years before the expected launch of flibanserin.

The effort was successful at increasing physician acceptance of HSDD. A study conducted by Pri-Med, a medical education and communication company that is a vendor to industry, found that live CME activities funded by Boehringer Ingelheim on hypoactive sexual desire disorder increased the percentage of primary care clinicians who indicated that they would screen for hypoactive sexual desire disorder. The study was presented at 
the 2011 annual meeting of the American College of Obstetricians and Gynecology. ${ }^{34}$

Sprout Pharmaceuticals has carried on the tradition. A search for recent web-based CME modules on hypoactive sexual desire disorder revealed three CME modules funded by Sprout Pharmaceuticals. $^{35}$ More CME modules can be expected. Palatin Technologies is testing bremelanotide, an injected melanocortin receptor, designed to be injected subcutaneously on an as-needed basis for female sexual dysfunction. In addition, a biotech called Emotional Brain, based in the Netherlands, is planning Phase II trials of two drug combinations, Lybrido (testosterone and sildenafil) and Lybridos (testosterone and buspirone), for hypoactive sexual desire disorder. ${ }^{36}$

Hypoactive sexual desire disorder is a typical example of the medicalisation of a normal state. The commercial practice of creating or expanding the market for a drug by convincing physicians and other prescribers that an 'unmet need' exists relies on industryfunded CME. Messages in CME may be subtle-for example, fostering specific diagnoses rather than specific drugs-and may go undetected by CME accreditors and audiences alike. The fact that accredited CME modules may be used to establish questionable conditions is concerning and deserves both more research and more discussion. If additional research confirms that industryfunded education on diseases and their treatments contain marketing messages, the question of whether all industry sponsorship of medical and CME should be banned must be seriously considered.

Acknowledgements Thanks to Nicole Dubowitz, Heather Hopkins and Alicia Bell for assistance with the manuscript.

Contributors All authors contributed to the intellectual content and writing of this article, and have approved the final content.

Competing interests AF-B is a paid expert witness at the request of plaintiffs in litigation regarding pharmaceutical marketing practices, and directs Pharmed Out, a Georgetown University Medical Center project that encourages rational prescribing. AM and EY completed this work in 2010 as graduate interns for PharmedOut. They received academic credit for their internships. A brief 5 min presentation based on this work was presented to the Food and Drug Administration Reproductive Health Drugs Advisory Committee on 18 June 2010.

Provenance and peer review Not commissioned; externally peer reviewed.

\section{REFERENCES}

1 Angelmar R, Angelmar S, Kane L. Building strong condition brands. J Med Mark 2007;(7):341-51.

2 Parry V. The art of branding a condition. Med Mark Media 2003;38(5):43-6.

3 Deer B. Sex drugs \& rock' $n^{\prime}$ roll. The Sunday Times Magazine 6 Sept 1998. http:/l briandeer.com/pfizer-viagra-1.htm

4 Lexchin J. Bigger and better: how Pfizer redefined erectile dysfunction. PLoS Med 2006;3(4):e132.

5 Moynihan R. The making of a disease: female sexual dysfunction. BMJ 2003;326:45-7.

6 Tiefer L. Female sexual dysfunction: a case study of disease mongering and activist resistance. PLoS Med 2006;3(4):178.

7 Moynihan R. The marketing of a disease: female sexual dysfunction. BMJ 2005;330 (7484):192-4.

8 American Psychiatric Association. Diagnostic and statistical manual of mental disorders. 4th edn. Washington DC: American Psychiatric Press, 2000.

9 IsHak WW, Tobia G. DSM-5 Changes in Diagnostic Criteria of Sexual Dysfunctions. Reprod Sys Sex Dis 2013;2:122.

10 Grogan K. Sprout resubmits 'female Viagra' to FDA. Pharma Times, 27 Jun 2013. http://www.pharmatimes.com/Article/13-06-27/Sprout_resubmits_female_Viagra_ to_FDA.aspx

11 Thacker P. How to Handle FDA Rejection. Slate, 6 Apr 2014. http://www.slate.com/ articles/double_x/doublex/2014/04/female_viagra_and_the_fda_the_agency_s_ rejection_of_flibanserin_has_nothing.html
12 Fugh-Berman A, Melnick D. Off-label promotion, on-target sales. PLoS Med 2008;5 (10):210.

13 Moynihan R. Merging of marketing and medical science: female sexual dysfunction. BMJ 2010;341:c5050.

14 Moynihan R, Mintzes B. Sex, lies, and pharmaceuticals: how drug companies plan to profit from female sexual dysfunction. Sydney, Australia: Allen and Unwin Pty Ltd., 2010.

15 Wysocki S, Kellogg-Spadt S, Kingsberg SA, et al. Talking to Female Patients about Sexual Health: Overcoming Common Communication Challenges. Medscape. Released: 25 May 2010. Expires 25 May 2011. http://cme.medscape.com/ viewarticle/721398 (accessed 17 Aug 2013).

16 Bachmann GA, Kellogg-Spadt S. Communication Strategies in Assessing Sexual Health: The Short Interview-Uncovering the need for a Long interview. Medscape and the University of Medicine \& Dentistry of New Jersey. Released 3 Feb 2010. Expires 3 Feb 2011. http://cme.medscape.com/viewarticle/713409 (accessed 17 Aug 2013).

17 Bailey LA, Krychman ML. Communication Strategies in Assessing Sexual Health: Uncovering an Underlying Condition. Medscape and the University of Medicine \& Dentistry of New Jersey. Released 11 Feb 2010. Expires 11 Feb 2011. http://cme. medscape.com/viewarticle/712564 (accessed 17 Aug 2013).

18 Kingsberg SA, Kellogg-Spadt S. The Essentials of Assessing the Sexual Concerns of Your Female Patients. Medscape and the University of Medicine \& Dentistry of New Jersey. Released 2 Feb 2010. Expires 2 Feb 2011. http://cme.medscape.com/ viewarticle/710343 (accessed 17 Aug 2013).

19 Green MA, Martinez LA. Female Sexual Dysfunction: Recognizing the Impact on Patient and Partner. Medscape. Released 21 May 2010. http://cme.medscape.com/ viewarticle/721520 (accessed 17 Aug 2013).

20 Pillai-Friedman S. Barriers to Communication About Female Sexual Health: Tips for Successful Dialogue with Patients. Medscape. Released 21 May 2010. http://cme. medscape.com/viewarticle/721521 (accessed 17 Aug 2013).

21 Kingsberg SA (author), Bachmann GA (peer-reviewer). Diagnosis and Classification of Female Sexual Dysfunction. Baylor College of Medicine. Released Aug 2008. Expires Aug 2010.

22 Kingsberg SA. Vaginismus and Hypoactive Sexual Desire Disorder in a Young Woman. Baylor College of Medicine. Released May 2009. Expired May 2010.

23 Kingsberg SA, Simon JA. Hypoactive sexual desire disorder in women: implications for family practice. Suppl J Fam Pract 2009;58(7). Released 15 July 2009. Expires 15 July 2010.

24 Cox R, Moore LF. Empowering PAs to ask their female patients about sexual health. JAAPA 2010;23:19-21, 46.

25 Kingsberg SA, Altman AM, Parish SJ. Sexuality, assessment and treatment of hypoactive sexual desire disorder. Sex Reprod Menopause 2010;8(1). Online version released 1 Feb 2010. Expires 1 Feb 2011.

26 Clayton AH, Brotto L, Kingsberg SA, et al. The Science and Medicine of Hypoactive Sexual Desire Disorder (HSDD). The University of Massachusetts Medical School, Pharmatecture LLC, CMEducation Resources LLC. Released 18 May 2010. Expires 18 May 2012. http://www.clinicalwebcasts.com/cvr/117.htm (accessed 17 Aug 2013).

27 Levine SB. Hypoactive sexual desire disorder in women. Presentation at 22nd Annual U.S. Psychiatric and Mental Health Congress Conference and Exhibition 4 Nov 2009. (CME LLC).

28 Wysocki S. Women's Sexual Health, Addressing Low Libido. Released 3 May 2010. Expires 3 May 2012. CMEcorner.com.

29 Fugh-Berman A, Dodgson S. The ethics of publication planning in the pharmaceutical industry. Open Med 2008;4(5):40-3.

30 Laumann E, Paik A, Rosen R. Sexual dysfunction in the United States: prevalence and predictors. JAMA 1999;281(6);537-44.

31 Female Sexual Function Index. 2000. http://www.fsfi-questionnaire.com (accessed 17 Aug 2013).

32 Frühauf S, Gerger H, Schmidt HM, et al. Efficacy of psychological interventions for sexual dysfunction: a systematic review and meta-analysis. Arch Sex Behav 2013; 42(6):915-33.

33 Stadler T, Bader M, Ückert $S$, et al. Adverse effects of drug therapies on male and female sexual function. World J Urol 2006;24(6):623-9.

34 Live Meetings Sway MDs to Screen for HSDD. Physician's Weekly, 28 Jun 2012 http://www.physiciansweekly.com/female-sexual-disorder/

35 Omnia Education. Hypoactive sexual desire disorder: Assessment, diagnosis and treatments; Hypoactive sexual desire disorder: Issues and answers, fact and fiction; Hypoactive sexual desire disorder: Diagnosing and managing the most common female sexual dysfunction. ReachMD. http://www.omniaeducation.com/CME_ EventGroup.asp?eventGroupCode=737L7B14024 (accessed 23 Aug 2014).

36 Scudellari M. That loving feeling. The Scientist, 1 Jul 2014. http://www.the-scientist. com/?articles.view/articleNo/40272/title/That-Loving-Feeling 